\title{
How Should General Surgery Education be? Trying to Find an Answer to the Long-term Problem Based on Prospective Evaluation of a General Surgeon's Education
}

\author{
Y. S. PEKER* \\ Department of General Surgery, Gulhane School of Medicine, University of Health Sciences, 06010, Ankara, Turkey
}

Peker: How should general surgery residency education be?

\begin{abstract}
Many debates about surgery education suggested that by analysing the educational programs of timetested, experienced centres. Educational data from a general surgery resident (type, number of surgeries, meetings, courses attended) at an urban university hospital were collected prospectively (2011-2016) and compared with consultancy career (2016-2018) in terms of annual mean values. The attendant participated in a total of 216.8 and 259.5 surgeries per year during his residency and consultancy $(p=0.132)$, respectively. The $95 \%$ confidence interval for annual mean percentage difference between residency and consultancy for 32 types of surgeries was $15-160 \%$. The attendant participated in an annual mean of 2.6 and 6.2 courses and 6.4 and 7.5 meetings during residency and consultancy, respectively $(p=0.465)$. No statistical difference between residency and consultancy in terms of attendance to educational facilities and operations was found. This indicated that the consultant specialized early and is still receiving selftailored education. This result is also the outcome when the percentage difference in annual mean value of 32 types of surgeries is evaluated. Surgical residency training must be professionally planned, standardized and successfully applied. Working in surgery is a lifestyle and needs trainers of a special character, so local interviews should be done in addition to nation-wide examinations. Continuous medical education and early specialization is the backbone of current surgical education and should be replaced with a Haldestrian approach under the supervision of multiple mentors.
\end{abstract}

Key words: Continuous medical education, early specialization, general surgery residency, surgical training

General surgery and internal medicine are the basis of medicine. Between these two branches, the history of general surgery is not as long as that of internal medicine due to operation sites infections and the absence of anesthesiology. Treating patients with drugs, especially drugs derived from herbs, was much easier than performing surgery for ancient physicians. Complex surgical procedures experienced exponential improvement with the development of antibiotics and anesthesiology, especially after late 1800 s. Before that, simpler local surgical procedures were applied. Among the first surgical procedures are circumcision and trepanation, which is drilling of a hole into the skull ${ }^{[1]}$. Trepanation likely was applied to liberate demons in the head. Skulls from 6500 B.C. in Peru were found to have undergone trepanation ${ }^{[2]}$. Substantial evidence showed that trepanation was applied around the world, from China to Egypt. Even Hippocrates, who lived between
460-375 B.C., encouraged trepanation, especially for blunt head trauma ${ }^{[3-5]}$.

After the early 1900 s, with the discovery of penicillin by Alexander Fleming in 1928, modern surgical operations started with a reduction in surgical site infections causing sepsis ${ }^{[6]}$. Improvement of anesthesiology also furthered the development of general surgery, especially after the establishment of modern anesthesiology in $1942^{[7]}$. With improvement of technology, surgery became a multidisciplinary field that is closely associated with technological advances, anaesthesiology, oncology, endocrinology, and the demands of the market. This resulted in surgery dividing into main branches, such as cardiovascular surgery, plastic and reconstructive surgery, urology, orthopedics, obstetrics and gynecology surgery and neurosurgery. However, this main branching was not enough for a general surgery specialization; knowledge 
even for the remaining aspects of general surgery was so great and multidisciplinary that sub-branching, such as oncological surgery, gastrointestinal surgery, breast and endocrine surgery and laparoscopic surgery/ minimally invasive surgery was established. However, sub-branching of general surgery is not standardized as it is in internal medicine and may differ between countries.

Such rapid development of general surgery resulted in educational challenges. There are many debates about residency education in general surgery around the world and it is hard to find the most appropriate. The only fact about education in general surgery is the mentor-apprentice relationship, which makes surgical educational more difficult and more precious. This problem can be solved by analyzing the educational programs of time-tested, experienced surgical clinics and centers. Surgical residency education is standardized in Turkey under the supervision of the Ministry of Health and Council of Higher Education and with the endorsement of the Turkish Surgical Association. In this study, the Turkish general surgery residency education was prospectively scrutinized in comparison with that in other countries, especially the education system and program of Stanford Medical School. A medical doctor attendant's residency and consultancy career data was used prospectively at a high-capacity urban hospital located in Turkey.

Educational data for a general surgery resident educated between August 2011 and August 2016 at the University of Medical Sciences, Gulhane Training and Research Hospital, were collected prospectively. Collected data included type and number of surgeries in which the attendant participated as either first surgeon or the second surgeon and the number of scientific meetings and courses in which the attendant took part. The same parameters were also collected prospectively during his consultancy career between August 2016 and August 2018 at the same hospital. The 2 periods were compared in terms of annual mean numbers of operations, courses, and scientific meetings during the attendant's residency career of $5 \mathrm{y}$ and consultancy career of 2 y. A total of 32 surgery types were also compared individually. Upper and lower limits of the $95 \%$ confidence interval for percentage difference using mean and standard deviation were calculated. The statistical data analysis comparing the residency career and consultancy career is discussed and compared with the Stanford University Medical Center residency program for further discussion.
The statistical analysis was done with SPSS version 22.0 (IBM SPSS Statistics for Windows, Armonk, NY). Before comparing the number of surgeries, courses and scientific meetings during attendant's residency and consultancy, it was determined by Shapiro-Wilk distribution test that the data set did not meet the normality assumption. The Wilcoxon test was used to compare the non-parametric data set. Statistical significance was accepted at $\mathrm{p}<0.05$.

The attendant participated in a total of 1084 surgeries during his residency. Each type of surgery during residency and consultancy and their percentage difference in terms of annual mean value is also given (Table 1). The attendant participated on average in 216.8 surgeries per year during residency. He was the first surgeon in 492 surgeries, under the supervision of a trainer, and second surgeon for the remaining operations; he was the first surgeon for $45.4 \%$ of surgeries. During his 2 y of consultancy, he participated in 519 surgeries with an annual mean of 259.5 . He was the first surgeon for 261 surgeries $(50.3 \%)$ and as a second surgeon for the remaining operations. The annual mean number of operations during residency and consultancy were compared and were found to be not significantly different using the Wilcoxon test.

The annual mean percent difference between residency and consultancy career for 32 types of surgeries is also evaluated (Table 1). The lower and upper limits of the $95 \%$ confidence interval comparing the annual mean percent differences across each type of surgery between residency and consultancy were 15 and $160 \%$ (Table 2). Table 1 shows that 21 out of 32 types had a higher annual mean of operations participated and 11 out of 32 had a lower annual mean of operations participated. The attendant never participated in portal catheter displacement or extra hepatic bile duct surgery during his consultancy, although he did participate in them during his residency; he never participated in dialysis catheter displacement surgery during his residency, although he did participate during his consultancy. The highest annual mean number of surgeries that he participated during his consultancy compared to residency was found in circumcision, lymph node dissection, and bariatric surgery.

The annual mean percent differences for educational facilities in which the attendant participated during $5 \mathrm{y}$ of residency and $2 \mathrm{y}$ of consultancy were calculated. Educational facilities included courses, local meetings and international meetings (Table 3). Educational facilities during residency and consultancy were 
TABLE 1: TOTAL NUMBER OF OPERATIONS PARTICIPATED BY THE ATTENDANT DURING RESIDENCY AND CONSULTANCY

\begin{tabular}{|c|c|c|c|c|}
\hline Type of surgery & $\begin{array}{l}\text { Residency } \\
\text { (per year) }\end{array}$ & $\begin{array}{c}\text { Consultancy (per } \\
\text { year) }\end{array}$ & $\begin{array}{l}\text { Life-Time (per } \\
\text { year) }\end{array}$ & $\begin{array}{c}\text { \% Difference } \\
\text { (per year) }\end{array}$ \\
\hline Anal surgery & $61(12.2)$ & $30(15.0)$ & $91(13.0)$ & $22.95 \%$ \\
\hline Appendectomy & $207(41.4)$ & $68(34.0)$ & $275(39.3)$ & $-17.87 \%$ \\
\hline Renal transplantation & $10(2.0)$ & $1(0.5)$ & $11(1.6)$ & $-75.00 \%$ \\
\hline $\mathrm{CRC} / \mathrm{HIPEC}$ & $5(1.0)$ & $3(1.5)$ & $8(1.1)$ & $50.00 \%$ \\
\hline Spleen & $6(1.2)$ & $3(1.5)$ & $9(1.3)$ & $25.00 \%$ \\
\hline Explorative surgery & $45(9.0)$ & $13(6.5)$ & $58(8.3)$ & $-27.78 \%$ \\
\hline Femoral hernia & $2(0.4)$ & $2(1.0)$ & $4(0.6)$ & $150.00 \%$ \\
\hline Small bowel surgery & $34(6.8)$ & $11(5.5)$ & $45(6.4)$ & $-19.12 \%$ \\
\hline İnguinal herniorapphy & $79(15.8)$ & $89(44.5)$ & $168(24.0)$ & $181.65 \%$ \\
\hline Colon surgery & $64(12.8)$ & $27(13.6)$ & $91(13.0)$ & $5.47 \%$ \\
\hline Liver surgery & $32(6.4)$ & $5(2.5)$ & $37(5.3)$ & $-60.94 \%$ \\
\hline Breast surgery & $99(19.8)$ & $18(9.0)$ & $117(16.7)$ & $-54.55 \%$ \\
\hline Gastric surgery & $31(6.2)$ & $18(9.0)$ & $49(7.0)$ & $45.16 \%$ \\
\hline Bariatric surgery & $5(1.0)$ & $6(3.0)$ & $11(1.6)$ & $200.00 \%$ \\
\hline Esophagectomy & $2(0.4)$ & $2(1.0)$ & $4(0.6)$ & $150.00 \%$ \\
\hline Pancreatic surgery & $8(1.6)$ & $6(3.0)$ & $14(2.0)$ & $87.50 \%$ \\
\hline Parathroidectomy & $11(2.2)$ & $1(0.5)$ & $12(1.7)$ & $-77.27 \%$ \\
\hline Rectal surgery & $40(8.0)$ & $6(3.0)$ & $46(6.6)$ & $-62.50 \%$ \\
\hline Extrahepatic bile duct surgery & $3(0.6)$ & $0(0.0)$ & $3(0.4)$ & $-100.00 \%$ \\
\hline Laparoscopic cholecystectomy & $143(28.6)$ & $74(37.0)$ & $217(31.0)$ & $29.37 \%$ \\
\hline Choledochotomy & $1(0.2)$ & $1(0.5)$ & $2(0.3)$ & $150.00 \%$ \\
\hline Surrenalectomy & $3(0.6)$ & $1(0.5)$ & $4(0.6)$ & $-16.67 \%$ \\
\hline Thyoidectomy & $49(9.8)$ & $21(10.5)$ & $70(10.0)$ & $7.14 \%$ \\
\hline Vacuum assisted closure techniques & $31(6.2)$ & $25(12.5)$ & $56(8.0)$ & $101.61 \%$ \\
\hline Ventral herniorraphy & $46(9.2)$ & $34(17.0)$ & $80(11.4)$ & $84.78 \%$ \\
\hline Circumcision & $1(0.2)$ & $3(1.5)$ & $4(0.6)$ & $650.00 \%$ \\
\hline Pilonidal cyst excision & $27(5.4)$ & $17(8.5)$ & $44(6.3)$ & $57.41 \%$ \\
\hline Lymph node dissection (axillary, inguinal, others) & $3(0.6)$ & $7(3.5)$ & $10(1.4)$ & $483.33 \%$ \\
\hline $\begin{array}{l}\text { Soft tissue excision (lipoma, intra-abdominal, } \\
\text { others) }\end{array}$ & $29(5.8)$ & $19(9.5)$ & $48(6.9)$ & $63.79 \%$ \\
\hline Wound revision & $6(1.2)$ & $7(3.5)$ & $13(1.9)$ & $191.67 \%$ \\
\hline Port catheter displacement & $1(0.2)$ & $0(0.0)$ & $1(0.1)$ & $-100.00 \%$ \\
\hline Dialysis catheter displacement & $0(0.0)$ & $1(0.5)$ & $1(0.1)$ & $50.00 \%$ \\
\hline Total & $1084(216.8)$ & $519(259.5)$ & $1603(229.0)$ & $16.45 \%$ \\
\hline
\end{tabular}

TABLE 2: STASTICAL PARAMETERS AND $95 \%$ CONFIDENCE INTERVALS FOR COMPARISON OF DIFFERENCES IN EACH SURGERY TYPE PARTICIPATED DURING RESIDENCY AND CONSULTANCY

\begin{tabular}{|c|c|c|c|}
\hline \multirow{4}{*}{$\begin{array}{l}\text { \% Differences between numbers of surgeries during residency and } \\
\text { consultancy }\end{array}$} & \multicolumn{2}{|l|}{ Mean } & 0.6855 \\
\hline & \multicolumn{2}{|c|}{ Standard deviation } & 1.6028 \\
\hline & $95 \%$ confidence intervals & Lower limit & 0.1547 \\
\hline & for mean & Upper limit & 1.6028 \\
\hline
\end{tabular}

statistically compared and found to be not significantly different using the Wilcoxon test. However, it can be understood from the results that the attendant participated in courses and international meetings during his consultancy more than during residency and participated in local meetings more during his residency than during consultancy. The data on educational facilities during residency and consultancy were not compared using percentage differences in terms of annual mean values according to $95 \%$ confidence interval because of the small number of parameters, which will prevent statistical significance.

The most important content in surgical education is discipline and professionalism, where professional competence is the habitual and judicious use of communication, knowledge, technical skills, clinical reasoning, emotions, values, and reflection in daily practice for the benefit of the individual and community being served ${ }^{[8]}$. This definition correctly encompasses 
TABLE 3: PARTICIPATION IN EDUCATIONAL FACILITIES WITH OR WITHOUT PRESENTING ABSTRACTS DURING RESIDENCY AND CONSULTANCY CAREER

\begin{tabular}{|c|c|c|c|c|c|}
\hline & & $\begin{array}{c}\text { Residency (per } \\
\text { year) }\end{array}$ & $\begin{array}{c}\text { Consultancy (per } \\
\text { year) }\end{array}$ & $\begin{array}{l}\text { Life-Time (per } \\
\text { year) }\end{array}$ & $\begin{array}{c}\text { \% Difference } \\
\text { (per year) }\end{array}$ \\
\hline \multicolumn{2}{|c|}{ Courses } & $13(2.6)$ & $13(6.2)$ & $26(3.7)$ & 176.92 \\
\hline \multirow{2}{*}{ Local meetings } & Abstract & $13(2.6)$ & $4(2)$ & $17(2.4)$ & -23.07 \\
\hline & Attendance & $7(1.4)$ & $2(1)$ & $9(1.3)$ & -71.42 \\
\hline \multirow{2}{*}{ International meetings } & Abstract & $9(1.8)$ & $6(3)$ & $15(2.1)$ & 66.66 \\
\hline & Attendance & $3(0.6)$ & $3(1.5)$ & $6(0.9)$ & 150.00 \\
\hline \multicolumn{2}{|c|}{ Total meetings/courses } & $32(6.4)$ & $15(7.5)$ & $47(6.7)$ & 17.18 \\
\hline
\end{tabular}

the professionalism asked of surgery residents. As highlighted in the definition, professionalism for a graduated surgeon is directly related to the richness of a surgeon's knowledge and technical skills, which also encompass the quality of education the surgeon had. For this reason, a healthy community with professional medical workers/physicians is a result of high-quality medical and surgical education. Education is difficult to evaluate in terms of quality. As the complexity of the subject to be taught increases, the teaching of the subject becomes more difficult, and thus the evaluation of the teaching of the subject also becomes more difficult. Because surgery has many subtopics and 2 major topics of theoretical and practical education, surgery residency education programs are very complex. Furthermore, ethical subjects, patient management, psychological improvement and technical/technological knowledge are also topics a surgery resident should know. When trying to teach all of these topics in $5 \mathrm{y}$ of residency, it is certain that a well-programmed, intensive education schedule should be planned. For these reasons, surgical residency programs must be planned by surgeons who are also literate educators.

In addition to residency education, continuous medical education (CME) is a very important topic for surgical education. Because the data and the market improve very rapidly at present and after graduation from residency, a consultant surgeon should continue selfeducation and improvement by attending conferences and courses to stay up to date. Eulert emphasized the value of CME, stating "postgraduate education and training is not only a duty but should also be recognized as a right that every doctor should demand to be educated to the level of knowledge and skills needed to provide ideal patient care ${ }^{[9]}$. When the prospective data of the attendant surgical resident were evaluated for educational facilities, it was observed that there was no statistical difference between residency and consultancy in terms of annual mean attendance of educational facilities. This indicated the consultant is still receiving education to keep up to date. Although there seems to be no significant difference between the educational facilities of the two periods, it can easily be seen that the attendant participated in more global meetings during his consultancy than during his residency. This shows that after becoming a consultant and specializing in a specific area, the participant searched for more detailed and high-quality data. This result is supported when the courses attended during the 2 periods were compared. Courses attended during residency were basic, and courses attended during consultancy were advanced. All these data showed that surgical education is not only education during residency but is lifetime education. To be more assertive, postgraduate education for surgery is more important than residency education. The most important part of CME is that, in contrast to residency education programs, CME is a self-tailored program designed according to the consultant's choices and incomplete areas of education ${ }^{[10]}$. This is why surgery is not called a career but a lifestyle.

As stated above, surgical education principally has 2 aspects theoretical and practical training or experience. For surgeons, it is true that the more one participated in surgeries, the better the education he gets. This is the reason behind the emphasis of master councils for surgical education usually for a required minimum number of surgeries in which a resident must participate annually. According to the study results, there was no statistical difference between the surgeries in which the attendant participated during residency and consultancy. Furthermore, although there is no significant difference, the mean number of surgeries was greater for the consultant than for the resident. To avoid incorrect analysis of the data, it should be emphasized that during the residency and consultancy periods, the attendant was not paid a performance-based wage but instead was paid a fixed wage. Therefore, the attendant's ambition to participate in surgeries was not due to monetary concerns but rather to educational concerns. This resulted in an increased number of annual operations, which also showed the importance of postgraduate education as a part of CME. 
As surgical knowledge improved, specialization in general surgery started to branch. This resulted in surgeons participating certain operations to gain experience in selected areas of surgery. To evaluate early specialization, which is debated most these days, all types of operations were compared individually in terms of annual mean number of surgeries performed and percent difference was calculated. The confidence interval for percent difference among 32 different operations was found out to be $15-160 \%$; none of the decrease in percentage difference was statistically significant. Furthermore, the number of operations with greater percent difference was almost 2-fold the number of operations with lower percent difference. This is an outcome of surgeries performed annually during consultancy being more than those performed annually during residency but the actual difference is not statistically significant. However, the confidence interval range being positive showed that the operations with lower percent difference are those that are performed in lower numbers than the average, and thus the attendant took part in these operations in lower numbers than during consultancy. The same is true for operations more commonly performed during residency. The attendant participated more often in these operations during consultancy. In other words, the attendant tried to specialize early.

Early specialization programs for general surgery have been debated for the last 2 decades. These are important for postgraduate surgeons to feel comfortable and adequate during complex surgeries such as hepatopancreaticobiliary surgery, esophagectomy and advanced minimally invasive surgery. As the number of residents and the cost of operations increased, instead of prolonging residents' education with late specialization, early specialization became a more logical choice for better surgical education. A study evaluating the career of consultants graduating from Yale University found that early specialization or specialized consultants are dominant in academic careers $^{[11]}$. The American Board of Surgery, American Board of Thoracic Surgery, and Residency Review Committees for Surgery and Thoracic Surgery started the Early Specialization Program for surgical residency training and published the $10 \mathrm{y}$ results ${ }^{[12]}$. The report showed that Early Specialization Program graduates were more successful in passing the specialty exams, and both the program directors and the participants were satisfied with the program. This literature survey shows the importance of early specialization in surgical education. Even though the participant in our study did not have a standardized formal early specialization education for surgery, the statistical results indicated that he tended toward early specialization and progressed toward early specialization during his consultancy.

With these data on a Turkish surgical residency education in a high-capacity urban hospital, it was necessary to evaluate the wrong and the right in the program. To evaluate these data, general surgery residency at reference centers such as the Stanford Health Care residency education program (Stanford Medical School fourth ranked among the world's best medical schools) was examined ${ }^{[13]}$. The Stanford Health Care surgical residency program started with the Core Training Program, which included the first 2 y of residency. Residents are expected to be involved in 100-300 surgical operations per year, with a total of more than 1000 at the end of $5 \mathrm{y}$. Residents are educated in medical theory in lectures, case conferences, and radiology/pathology/tumor conferences. In the chief year of residency, the program aimed for the resident to be responsible for major surgeries to achieve the self-confidence necessary for a general surgeon. Residency education at Stanford is supported by hospital-wide conferences. The program included weekly gastrointestinal, breast, hepatobiliary and sarcoma tumor boards, case conferences, preoperative patient discussion conferences, surgery core course and morbidity-mortality conferences. In addition to inhospital conferences, residents are expected to attend local and global surgical meetings and congresses. The backbone of theoretical education of surgical residents depended on The Surgical Council on Residency Education (SCORE) Portal. The backbone of the surgical skill curriculum is the American College of Surgeons Surgery Skills Curriculum for residents. The same basis is used at the University of Medical Sciences, Gulhane Training and Research Hospital. Number of surgeries is almost the same, and the same style of weekly clinical and hospital-wide boards is used.

When comparing the two centers, no major difference was observed in the education program and mean numbers of lectures, operations and councils. What makes one center one of the most successful educational clinics and the other not? This is the matter in understanding surgical education. Both the United States and Turkey accept physicians into surgical residency programs with examinations. The difference is that Turkey accepts residents with a nationwide examination with no interviews or examinations done 
locally by the faculties or clinics. However, the US system allows universities or clinics to accept residents with local examinations and interviews, allowing educators to accept more qualified and compatible physicians ${ }^{[14]}$. This gave Stanford University the ability to hire more qualified residents for surgery residency programs, which resulted in better-educated consultants. This also allowed Stanford University to hire residents with a character and lifestyle more compatible with surgery and surgical education.

The Halstedian surgical education approach described when Halsted was working at Johns Hopkins Hospital has been the principle approach around the world since 1904, with its adage 'see one, do one, teach one ${ }^{\text {'[15]. }}$ This approach needed to be changed over time with the improvement in modern surgical approaches, closely related to technology, ethics, law and the market. The surgical education system was mainly under the influence of Europe until the end of the 19th century, with the rise of the influence of the United States and the Halstedian approach. This is also a result of US medical technological improvement outpacing European improvements. These new interventions made the United States revise its surgical education residency system and discuss the topic at committees and organizations. The classical education system defined by Halsted featured heavily working residents in close contact with surgical mentors and completely under the supervision of surgical mentors. Education of residents was related to how close the resident is with the surgical mentor and was limited to the patient portfolio and educational borders of the surgical mentor. Training in surgical theory was also limited to the knowledge of the surgical mentor because residents did not have time for research and reading textbooks as a result of long work hours and duties. This is also known as mentor-disciple surgical education.

This type of education was not enough for surgical residents after the development of substantial new medical data, new surgical devices and new surgical techniques such as laparoscopy and robotic surgery. Standardization studies resulted in the definition of core competencies of surgical residency education by the Accreditation Council for Graduate Medical Education in 1999. This also resulted in the development of early specialization terminology. Competencies of surgical residency education by the Accreditation Council for Graduate Medical Education are patient care, communication skills, medical knowledge, practice- based learning, professionalism and improvement ${ }^{[15]}$. The main technique for covering patient care, communication skills and medical knowledge is by councils and lectures, which are standardized, given by different mentors and allow the resident to choose the correct mentor and role model for each educational topic. This in turn allows the resident to build the best data/ experience during residency. Professionalism may also be addressed in lectures and mentor-disciple relations and it should be remembered that professionalism is also related to the personal character of the resident. Practice-based learning is provided during the time the resident spends in the operating room.

Although the education programs of the 2 centers compared here are the same, there is a difference between the 2 centers when rankings were compared. This is because surgical education is a multifactorial and complicated topic. For this reason, surgical residency training must be professionally planned, standardized and successfully applied during training. However, well-planned and standardized education that is successfully applied is not enough to produce welleducated surgeons. One of the most important factors is the character of the trainees themselves. Surgery is not only a career but also a lifestyle that needs trainers of a special character to be risk bearers, team workers and a calm presence. Therefore, while accepting trainers for surgical education, local interviews done by mentors are the most important aspect. Even though planned and standardized education for surgery is important, personal effort to tailor education to be suitable for the trainee (note that this does not differ for resident or consultant) is a major part of the program.

The Halstedian surgical education approach is the basis of first modern surgical education but has to be revised with CME and early specialization approaches, with multidisciplinary education of the trainees under the supervision of multiple mentors, each specialized in different sub-branches of surgery.

According to Riegler, 'teaching and education in surgery compares to the care required for the maintenance of a garden, where passion and discipline foster respective support and motivation to those who wish to flourish and bloom: true for a teacher and a scholar ${ }^{[16]}$. All surgical mentors are responsible for training new surgeons, who may treat those mentors who educated them as a part of family. Thus, training is not only a matter of daily work life but it is also a personal matter and a national matter. 


\section{Conflict of interest:}

The authors declare that they have no conflict of interest.

\section{REFERENCES}

1. Lador R, Liberman S, Ben-Galim P, Dreiangel N, Reitman CA, Hipp JA. A cadaver study to compare vertebral augmentation with high-viscosity cement to augmentation with conventional lower -viscosity cement. J Spinal Disord Tech 2013;26:68-73.

2. Georgy BA. Clinical experience with high-viscosity cements for percutaneous vertebral body augmentation: occurrence, degree, and location of cement leakage compared with kyphoplasty. AJNR Am J Neuroradiol 2010;31:504-8.

3. Wang H, Sribastav SS, Ye F, Yang C, Wang J, Liu H, et al. Comparison of highviscosity cement vertebroplasty and balloon kyphoplasty for the treatment of osteoporotic vertebral compression fractures. Pain Physician 2015;18:E187-94.

4. Trumm CG, Jakobs TF, Stahl R, Sandner TA, Paprottka PM, Reiser MF, et al. CT fluoroscopy-guided vertebral augmentation with a radiofrequency -induced, high-viscosity bone cement (StabiliT): technical results and polymethylmethacrylate leakages in 25 patients. Skeletal Radiol 2013;42:113-20.

5. Kim JM, Shin DA, Byun DH, Kim HS, Kim S, Kim HI. Effect of Bone Cement Volume and Stiffness on Occurrences of Adjacent Vertebral Fractures after Vertebroplasty. J Korean Neurosurg Soc 2012;52:435-40.

6. Zhang L, Wang J, Feng X, Tao Y, Yang J, Wang Y, et al. A comparison of high viscosity bone cement and low viscosity bone cement vertebroplasty for severe osteoporotic vertebral compression fractures. Clin Neurol Neurosur 2015;129:10-6.

7. Baoqiu LI. Percutaneous vertebroplasty for acute severe osteoporotic vertebral compression fractures with high viscosity bone cement. Laser J 2013;34:118-9.

8. Guo D, Cai J, Zhang S, Zhang L, Feng X. Treating osteoporotic vertebral compression fractures with intraosseous vacuum phenomena using high-viscosity bone cement via bilateral percutaneous vertebroplasty. Medicine 2017;96:e6549.
9. Nieuwenhuijse MJ, Muijs SP, van Erkel AR, Dijkstra SP. A Clinical Comparative Study on Low vs. Medium Viscosity PMMABone Cement in Percutaneous Vertebroplasty: Viscosity Associated with Cement Leakage. Spine 2010;10:S118-9.

10. Nieuwenhuijse MJ, Van Erkel AR, Dijkstra PS. Cement leakage in percutaneous vertebroplasty for osteoporotic vertebral compression fractures: identification of risk factors. Spine J 2011;11:839-48.

11. Yang DT, Zhang D, Arola DD. Fatigue of the bone/cement interface and loosening of total joint replacements. Int J Fatigue 2010;32:1639-49.

12. Rotter R, Schmitt L, Gierer P, Schmitz KP, Noriega D, Mittlmeier $\mathrm{T}$, et al. Minimum cement volume required in vertebral body augmentation-A biomechanical study comparing the permanent SpineJack device and balloon kyphoplasty in traumatic fracture. Clin Biomech 2015;30:7205 .

13. Cui W, Liu B, Wang L, Kang W, Chen B. The correlation analysis of balloon volume and bone cement volume in percutaneous kyphoplasty. Chin J Surg 2015;53:289-93.

14. Chen HG, Chen JP, Liang HP, Kong QZ, Chen JH, Zhou Y, et al. Retrospective study on volume of bone cement injection for concurrent of fracture after thoracolumbar vertebraes kyphoplasty. Chin J Orthop Trauma 2012;25:681-83.

15. Kim JM, Shin DA, Byun DH, Kim HS, Kim S, Kim HI, et al. Effect of Bone Cement Volume and Stiffness on Occurrences of Adjacent Vertebral Fractures after Vertebroplasty. J Korean Neurosurg Soc 2012;52:435-40.

This is an open access article distributed under the terms of the Creative Commons Attribution-NonCommercial-ShareAlike 3.0 License, which allows others to remix, tweak, and build upon the work non-commercially, as long as the author is credited and the new creations are licensed under the identical terms

This article was originally published in a special issue, "Recent Trends in Biomedical Research" Indian J Pharm Sci 2020:82(1)spl issue1; XX-XX 